\title{
WORKLOAD AND HEALTH PROBLEMS IN MEDICAL STUDENTS
}

\author{
Maria Altaf, Kisa. F Altaf, Aaishah Iftikhar, Sharmeen Goha \& Yusra.
}

Fatima Jinnah \& Dental College

Dow university of Health Sciences, DUHS

Corresponding Author: maria3188@gmail.com

\begin{abstract}
The inability to cope successfully with the enormous stress of medical education may lead to a cascade of consequences at both a personal and professional level. Although common, depression associates with a high degree of disability and chronicity, with symptoms such as low mood, lack of energy, poor concentration, low self-esteem, and a lack of interest in the environment however stress has been shown to have deleterious effects on one's physical and mental well-being. The extreme stress levels inherent in the medical profession, put premedical and medical students at risk for both physical and psychological problems. The aim of this study is to determine the workload stress which leads to different health problems in medical and dental students during their undergraduate training. It was a self-administered questionnaire based survey conducted on 114 medical and dental students (32 males and 118 females) who were randomly selected in Fatima Jinnah Dental College and Dow University of Health Sciences. The result of this study shows that undergraduate medical students are suffering with stress and anxiety due to their hectic schedule and vast syllabus. From this study we can evaluate that health problems such as muscular aches and pains especially in neck, head, lower back and shoulders have increased which leads to sleep disorders. Data was analyzed using SPSS 20.0.This study suggests that a small percentage of medical students experience physical and mental distress throughout their medical undergraduate training.
\end{abstract}

\section{KEYWORDS}

Self-esteem, workload. Stress, medical students

\section{INTRODUCTION}

Medical undergraduate training is deep and emotionally demanding. Several studies have declared high rates of psychological distress (Firth-Cozens, 1987; Miller, 1991 \& Guthrie, 1995) in medical students at various stages of their training. Repeatedindication that medical students are prone to considerable stress has been published over the last decades (Firth-Cozens, 1989; Wallin, 2003 \& Aktekin, 2001). It has been demonstrated that mental distress during medical school forecasts later problems in physicians (Firth-Cozens J 1998; Tyssen $\mathrm{R}$ et al, 2001) which in addition to the personal agonyof the individual doctor might badly affect patient care (Firth-Cozens, 1997). Stress can be enhanced by one's personal system of beliefs, behaviors and attitudes. Stress can either motivate the student to peak performance or reduce their effectiveness in different degrees (Grandy, 1989). A number of factors-including academic pressure, workload, financial concerns, sleep deprivation, exposure to patients' suffering and deaths, student abuse, ( Silver,1990; Elnicki, 1999; Richman, 1992 \& Sheehan,1990) and a "hidden curriculum" of cynicism (Hafferty, 1998; Stern, 1998; Hafferty, 1994; Feudtner, 1994; Christakis, 1993; Wear, 1998; Hundert, 1996 \& Kassebaum, 1998) have been hypothesized to contribute to this decline in students' mental health. Typical sources of stress for dental students include frequent examinations, examination phobia, reduced leisure time, demanding curricula, requirements to perform specified types and numbers of procedures, anxious patients, time limits, complicated treatments, possible conflicts with patients, fellow students, staff and faculty, lack of self-confidence, and the differences between the students expectations and reality (Newton, 1994; Heath, 1999). This study found that the heavy workload, the repetitive nature of the work, fear and anxieties concerning treatment outcome and payment were all stress factors among general practitioners (GP) as well as other dentists. This agrees with other studies, reporting that occupational stress results when dentists find themselves overloaded with work. The overload can be either quantitative in nature (i.e., too much work to do) or qualitative (i.e., work is too difficult). (Sloan, 1986; Cox, 1980 \& Freeman, 1995)
According to a 2006 Mayo Clinic study, students enter medical school with mental health profiles similar to their peers from college. But they begin to show higher rates of mental distress as they progress through medical school. The same study found that the most depressed students often are the least likely to reach out for help because of stigma related to mental illness. Stuart Slavin, M.D., dean of student affairs at Saint Louis University School of Medicine (SLU), started working on a "multifactorial" approach when he found students at his own school showed a high prevalence of mental distress. At the same time, he considered the suicide rates of physicians compared with the general population -40 percent higher for male doctors and 130 percent higher for female doctors, according to a 2005 New England Journal of Medicine study. High levels of stress can result in a variety of physical and psychological distress which in turn can affect the well-being and performance of the student.

Symptoms of distress can include anxiety, depression, phobia, hostility, fear, tension, dizziness, fatigue, sleeplessness, tachycardia, gastrointestinal symptoms, irritability and cynicism (Hendricks, 1949; Tedesco, 1986; Westerman, 1993; Yap, 1996; Heath, 1999; Sanders, 1999; Rajab, 2001 \& Acharya, 2003). Furthermore, there is evidence that high stress levels impair the immune system function (Sanders, 1999).

\section{METHODOLOGY}

A cross sectional study was done on 114 medical students. Performa was distributed randomly to the medical and dental students from first year level to house officers, age ranges from 18-26 years .Data was collected from Fatima Jinnah dental college \& Dow University of Health Sciences, accommodation along with age, gender, personal problems and academic problems. Data was analyzed on SPSS 20.0, Excel 2007, and PowerPoint 2007 in which frequencies, percentages \& graphs were plotted. Graphs given below are related to their personal problems including Muscular Aches, addictive, worries, sleep disturbance, lack of time for social circle, lack of time for relaxation. 


\section{RESULTS}

Data was analyzed on 114 complete forms. Result demonstrates that there were 27 males and 87 females who filled the Performa. This study was divided into two subscales, the personal problems and the health problems to determine relationship between workload and health problems. My results shows that 88(77.2\%) students out of 114 complained about muscular aches they are facing, it's been a major problem for medical and dental students who are undergraduates, having their house jobs or practicing in clinics with standard deviation of $\pm 0.421,77(67.5 \%)$ about lack of time for friends/ family and ignorance of their interests, hobbies and entertainment, 35 $(30.7 \%)$ complains about addiction(increased intake of tea and coffee even smoking) with mean of 1.69 and standard deviation of \pm 0.464 , $94(82.5 \%)$ about lack of time for relaxation, $72(63.2 \%)$ worries too much, and 96(84.2\%) complained about their sleep disturbance (sleeplessness/ insomnia). Students also experience crying spells and grinding teeth, changed appetite and mood swings. The standard deviations mean, median, mode and standard errors are given in figure below.

Descriptive Statistics

\begin{tabular}{|c|c|c|c|c|c|c|}
\hline & $\mathrm{N}$ & Sum & Mean & & Std. Deviation & Variance \\
\hline & Statistic & Statistic & Statistic & Std. Error & Statistic & Statistic \\
\hline Lack of relaxation & 114 & 134 & 1.18 & .036 & .382 & . 146 \\
\hline $\begin{array}{l}\text { Intake of addicted things } \\
\text { (Caffeine.) }\end{array}$ & 113 & 191 & 1.69 & .044 & .464 & .216 \\
\hline Worrying too much & 114 & 156 & 1.37 & .045 & .485 & .235 \\
\hline Often dishearten & 114 & 149 & 1.31 & .043 & .463 & .215 \\
\hline Lack time for hobbies & 114 & 143 & 1.25 & .041 & .437 & .191 \\
\hline Lack time for family/friends & 114 & 151 & 1.32 & .044 & .470 & .221 \\
\hline Muscular Aches & 114 & 140 & 1.23 & .039 & .421 & .178 \\
\hline Sleep disturbance & 114 & 133 & 1.17 & .037 & .397 & .158 \\
\hline Change in appetite & 114 & 159 & 1.39 & .046 & .491 & .241 \\
\hline Valid N (list wise) & 113 & & & & & \\
\hline
\end{tabular}

Table \#1 showing descriptive statistics about personal and health problems

\section{DISCUSSION}

A student's life is subjected to different kinds of stressors, such as the pressure of academics with hindrance of success, uncertain future and complications envisaged for integration into the system. These students face social, emotional and physical and family problems which may affect their learning capability and academic performance (Fish, 1996; Chew-Graham, 2003). Some of them find it hard to cope with the stress and lag behind, while others see the pressure as challenge to work harder. . 64\% people can't take part because of lack of time due to their academic schedule or lack of interest. (Maria, 2013) Medical students particularly perceive themselves more likely to become ill in contrasts with others (Raj, 2000). Stress can lead to disruptions in both physical and mental health.

"By definition medical school is stressful," Slavin said. "We wanted to do what we could to reduce unnecessary stressors without compromising the quality of education."

Students experience psychological distress throughout their medical undergraduate training. Although these students found the first year of the medical course more stressful than did their fellow students, this was not true of subsequent years. It is possible that emotionally vulnerable in year 1 students find it more difficult than their peers to adjust to Base line changes and thus finds the first year at university particularly stressful.
There were some confirmations (not statistically significant), failed that psychological distress is associated with poor performance on the course, since those who failed examinations or dropped out had numerically lower grades in exams than those who intercalated (usually the brightest students) or continued through the course in an uninterrupted fashion. A larger study would be required to confirm or refute this possibility.

One of the demographic variables related to the problem scores was gender. Female students reported higher scores in both the overall problem score and the clinical problem score than males. This is especially evident in the top ranked problem items. Most of their perceived problems centered on the feeling of being overloaded, lack of time, and increased responsibilities.

My findings suggest that medical schools are currently admitting a small group of students who are distressed at the beginning of their training and may remain distressed throughout. These few individuals are at high risk of emotional disturbance during postgraduate training. Further work needs to be done so that they can be identified either before they have entered medical school or early in their medical training. 
With students showing such high levels of distress, Dyrbye said the burden of seeking help should not fall on them alone, adding that institutions should play an active role in helping students handle burnout or depression. "It's certainly important for the student to learn the right coping strategies, time management skills, and stress reduction techniques," Dyrbye said. "All of that is important, but it is not the entire answer. We also have to look at school-level initiatives. There needs to be organizational change."
Students living with their families had higher overall problem scores, and higher problem scores for the categories of personal and administrative issues and clinical training. These findings may be explained by lack of time and the increased demands of social activities that may limit time in general and lead to a feeling of being overloaded.

\section{Personal problems}

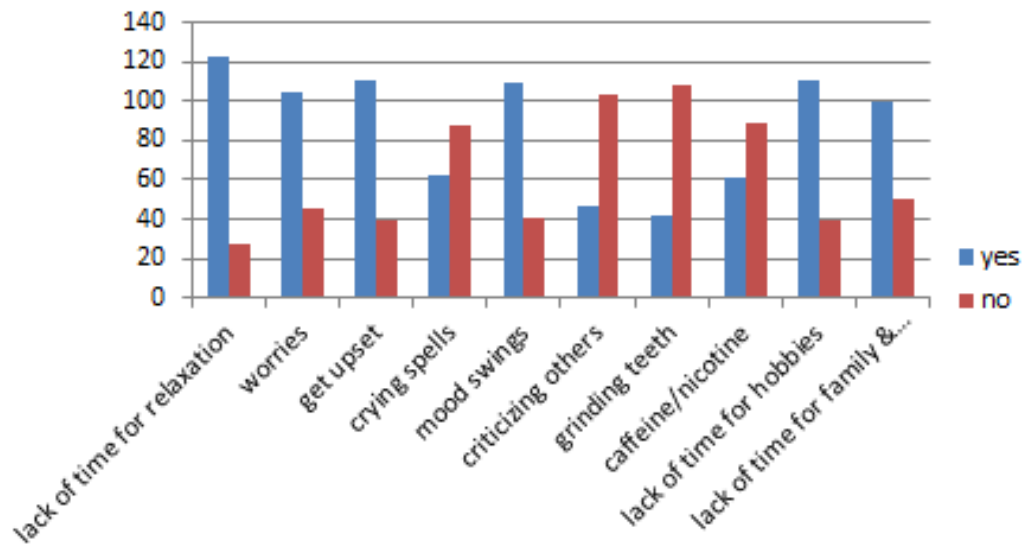

Graph\#1: Personal problems faced by doctors

\section{Health problems}

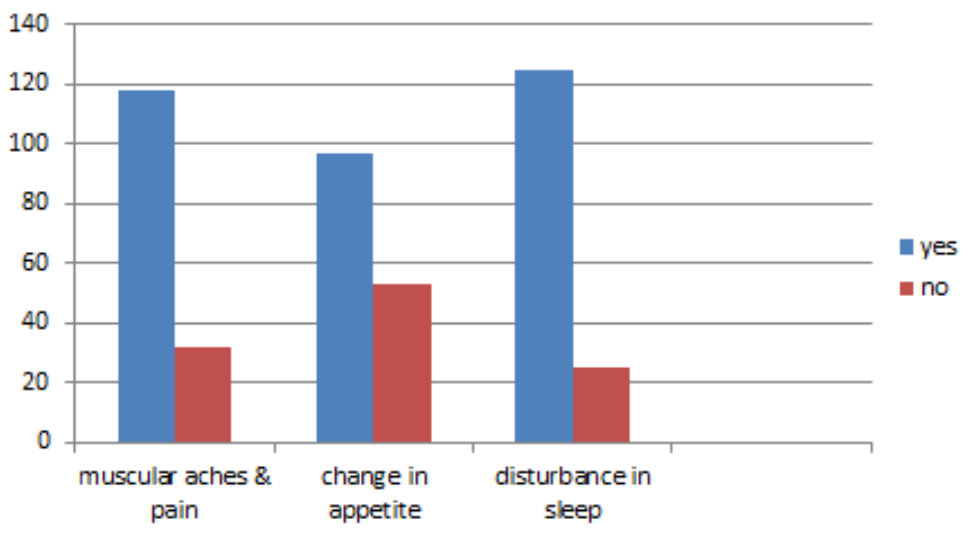

Graph\#2: Health problems faced by doctors. 


\section{CONCLUSION}

"We point out that distorted ways of thinking can have consequences," Fendell said. "If you can learn to think more accurately and rationally about a situation, it increases your options for how to respond."

\section{REFERENCES}

- Acharya, S. (2003). Factors affecting stress among Indian dental students. Journal of dental education, 67(10), 1140-1148.

- Aktekin, M., Karaman, T., Senol, Y. Y., Erdem, S., Erengin, H., \& Akaydin, M. (2001). Anxiety, depression and stressful life events among medical students: a prospective study in Antalya, Turkey. Medical education, 35(1), 12-17.

- Chew-Graham, C. A., Rogers, A., \& Yassin, N. (2003). 'I wouldn't want it on my CV or their records': medical students' experiences of help-seeking for mental health problems. Medical education, 37(10), 873-880.

- Christakis, D. A., \& Feudtner, C. (1993). Ethics in a short white coat: the ethical dilemmas that medical students confront. Academic Medicine, 68(4), 249-54.

- Cox, T. (1980). Repetitive work. In: Cooper CL, Payne R, eds. Current concerns inoccupational stress. Chichester: JohnWiley.

- Dyrbye, L.N., Thomas, M.R., Huntington, J.L., Lawson, K.L., Novotny, P.J., Sloan, J.A., \& Shanafelt, T.D. (2006) Personal life events and medical student burnout: a multicenter study. Acad Med, (81), 374-84.

- Elnicki, D. M., Linger, B. A. R. R. Y., Asch, E. R. I. C. A., Curry, R. A. Y. M. O. N. D., Fagan, M. A. R. K., Jacobson, E. R. I. C., ... \& Wallach, P. A. U. L. (1999). Patterns of medical student abuse during the internal medicine clerkship: perspectives of students at 11 medical schools. Academic Medicine, 74(10), S99-101.

- Feudtner, C., Christakis, D. A., \& Christakis, N. A. (1994). Do clinical clerks suffer ethical erosion? Students' perceptions of their ethical environment and personal development. Academic medicine, 69(8), 670-9.

- Firth, J. (1986). Levels and sources of stress in medical students. British medical journal (Clinical research ed.), 292(6529), 1177.

- Firth-Cozens, J. (1989). Stress in medical undergraduates and house officers.British journal of hospital medicine, 41(2), 161.

- Firth-Cozens, J. (1998). Individual and organizational predictors of depression in general practitioners. The British Journal of General Practice, 48(435), 1647.

- Firth-Cozens, J., \& Greenhalgh, J. (1997). Doctors' perceptions of the links between stress and lowered clinical care. Social science \& medicine, 44(7), 1017-1022.

- Fish, C. \& Nies, M.A. (1996). Health promotion needs of students in a college environment. Public health Nursing, 13, $104-111$.

- Freeman, R., Main, J. R., \& Burke, F. J. (1995). Occupational stress and dentistry: theory and practice. Part I. Recognition. British Dental Journal,178(6), 214-217.

- Grandy, T. G., Westerman, G. H., Combs, C. E., \& Turner, C. H. (1989). Perceptions of stress among third-year dental students. Journal of dental education, 53(12), 718-721.

- Guthrie, E. A., Black, D., Shaw, C. M., Hamilton, J., Creed, F. H., \& Tomenson, B. (1995). Embarking upon a medical career: psychological morbidity in first year medical students. Medical education, 29(5), 337-341.

- Hafferty, F. W. (1998). Beyond curriculum reform: confronting medicine's hidden curriculum. Academic Medicine, 73(4), 403-7.

- Hafferty, F. W., \& Franks, R. (1994). The hidden curriculum, ethics teaching, and the structure of medical education. Academic Medicine, 69(11), 861-71.
- Heath, J. R., Macfarlane, T. V., \& Umar, M. S. (1999). Perceived sources of stress in dental students. Dental update, 26(3), 94.

- Hendricks, S., Joshi, A., Crombie, K., Moola, M. (1949). Perceived sources of stress among black dental students in South Africa. J. Dent. Educ. (58), 406-410.

- Hundert, E. M., Hafferty, F., \& Christakis, D. (1996). Characteristics of the informal curriculum and trainees' ethical choices. Academic Medicine, 71(6), 624-42.

- Kassebaum, D. G., \& Cutler, E. R. (1998). On the culture of student abuse in medical school. Academic Medicine, 73(11), 1149-58.

- Maria, A., Kisa, F. (2013). Increasing obesity and its risk factors, International Journal of Endorsing Health Science Research, 1(1), 21-24.

- Miller, P., \& Surtees, P. G. (1991). Psychological symptoms and their course in first-year medical students as assessed by the Interval General Health Questionnaire (I-GHQ). The British Journal of Psychiatry, 159(2), 199-207.

- Newton, J. T., Baghaienaini, F., Goodwin, S. R., Invest, J., \& Lubbock, M. (1994). Stress in dental school: a survey of students. Dental update, 21(4), 162-164.

- Raj, S. R., Simpson, C. S., Hopman, W. M., \& Singer, M. A. (2000). Health-related quality of life among final-year medical students. Canadian Medical Association Journal, 162(4), 509-510.

- Rajab, L. D. (2001). Perceived sources of stress among dental students at the University of Jordan. Journal of dental education, 65(3), 232-241.

- Richman, J. A., Flaherty, J. A., Rospenda, K. M., \& Christensen, M. L. (1992). Mental health consequences and correlates of reported medical student abuse.JAMA: the journal of the American Medical Association, 267(5), 692-694.

- Sanders, A. E., \& Lushington, K. (1999). Sources of stress for Australian dental students. Journal of dental education, 63(9), 688697.

- Sheehan, K. H., Sheehan, D. V., White, K., Leibowitz, A., \& Baldwin Jr, D. C. (1990). A pilot study of medical student'abuse'. JAMA: the journal of the American Medical Association, 263(4), 533-537.

- Silver, H. K., \& Glicken, A. D. (1990). Medical student abuse. JAMA: the journal of the American Medical Association, 263(4), 527-532

- Stern DT. 1998 In search of the informal curriculum: when and where professional values are taught. Acad Med.73(10) 28-30

- Tedesco, L. A. (1986). A psychosocial perspective on the dental educational experience and student performance. Journal of dental education, 50(10), 601-605.

- Tyssen, R., Vaglum, P., Grønvold, N. T., \& Ekeberg, Ø. (2001). Factors in medical school that predict postgraduate mental health problems in need of treatment. A nationwide and longitudinal study. Medical education, 35(2), 110-120.

- Wallin, U., \& Runeson, B. (2003). Attitudes towards suicide and suicidal patients among medical students. European psychiatry, 18(7), 329-333.

- Wear, D. (1998). On white coats and professional development: the formal and the hidden curricula. Annals of Internal Medicine, 129(9), 734-737.

- Westerman, G. H., Grandy, T. G., Ocanto, R. A., \& Erskine, C. G. (1993). Perceived sources of stress in the dental school environment. Journal of dental education, 57(3), 225-231.

- Yap, A., Bhole, S., Teo, C., (1996). Across-cultural comparison of perceived sources of stress in the dental school environment. J. Dent. Educ.(60),459-464. 